\title{
sciendo
}

DOI 10.2478/sbe-2019-0035

SBE no. 14(2) 2019

\section{LOGISTICS AND SUPPLY CHAIN MANAGEMENT: AN OVERVIEW}

\author{
VACAR ANCA \\ Lucian Blaga University of Sibiu, Romania
}

\begin{abstract}
:
The purpose of this paper is to identify and explore the content of Logistics and Supply Chain Management, and to find the connections and the differentials factors that are between the two areas. The study is based on literature review and wants to find the core subjects and the differentials between the two areas, in order to a better and comprehensive understanding of these topics.
\end{abstract}

Key words: Logistics, Supply Chain Management, Management

\section{Introduction}

This paper is trying to develop a more thorough understanding of Supply Chain Management (SCM) and Logistics concepts. Following this introduction, the literature review provides an overview about the evolution of Supply Chain Management and Logistics and the relationship between them. At the end, the paper presents some conclusions about the concepts discussed, presenting common aspects and differentials found.

When we think about our daily activities and the fact that we are surrounded by things and products that help us to have a better and comfortable life, it's time to stop and think about how those things are produced and where the raw materials come from. To this problem, Supply Chain Management and Logistics can help find the answer.

\section{Evolution and definitions of Supply Chain Management and Logistics}

According to Larson and Halldorsson (2004), Supply Chain Management is the "integration of key business processes from end user through original suppliers that provides products, services, and information that add value for customers and other stakeholders". 
As Li (2014) reveals in his book, in the early 1960s, Jay Forrester, an MIT professor, studied the relationships in both directions between suppliers and customers and discovered the fact that inventories in a supply pipeline tend to oscillate more as they are at a greater distance from the customer, and this situation leading to either uncompleted orders or too much inventory. Another professor, Michael Porter, from Harvard Business School, suggested that organizations could be more competitive if they were better able to manage the whole activities upon which the current supply chain structure is built, namely the value chain and refers to all interrelationships between inbound logistics, outbound logistics, operations, sales, marketing and customers service.

According to the same $\mathrm{Li}$ (2014), Supply Chain Management is "a set of synchronized decisions and activities" used to integrate in a more efficient way the suppliers, the manufactures, the warehouses, all transporters involved, the retailers, and the final customers, all this helping that the right product or service will be available and distributed at the right quantities, at the right prices, to the right locations, in the right condition, and at the right time, in order to minimize system-wide costs while trying to satisfy customer requirements. And because of this, he mentions that the objective of Supply Chain Management is to achieve a sustainable competitive advantage.

Waters (2009) simply explains Supply Chain Management as "series of activities and organisations that materials move through on their journey from initial suppliers to final customers". In his point of view, every product has its own unique supply chain, and these can be short or long, simple or complicated. It can be a sum of connected entities involved together to offer to the final customer the product or service he claims and waits for. The supply chain can be presented also as a map that describes the total journey of materials as they move from one part to another. Along this journey, „materials may move through raw materials suppliers, manufacturers, finishing operations, logistics centres, warehouses, third party operators, transport companies, wholesalers, retailers, and a whole range of other operations" (Waters, 2009).

Another definition found for explaining Supply Chain Management, is given by Maia and Cerra (2009), as 'the integration of the main processes that manage materials and information flows" in both directions, within the enterprise and between the companies that take part into the supply chain until reaching the final consumers. The main goal of Supply Chain Management, according to them, is to aggregate value to the stakeholders and to the clients along these processes.

Also Li (2014) reveals that over time, the key driving force for moving from Material Management to Supply Chain Management was the Information Technology. He also explains very simply the stages of the business model evolution which is presented above in Figure 1., from Bill of Materials (BOM) processor appearing in the early 60s, Material Requirement Planning (MRP) entering the scene in the 70s, Manufacturing Resource Planning (MRPII) in the 80s, Enterprise Resource Planning (ERP) in the 90s, and Supply Chain Management (SCM) packages coming into use in the early 21 st century. So, as we have seen, the Advanced Technology had a great impact on managing materials and on Supply Chain Management along the way. 


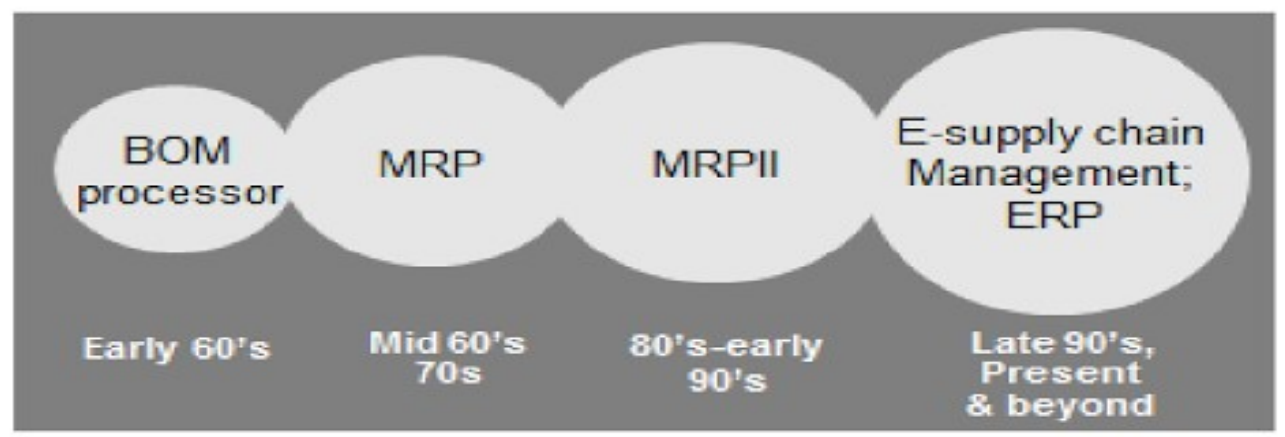

Figure 1. Evolution of e-supply chain

Source: Li, L. (2014), Managing Supply Chain and Logistics, Competitive Strategy for a Sustainable Future

According to specialists from Council of Supply Chain Management Professionals (CSCMP): 'Supply Chain Management encompasses the planning and management of all activities involved in sourcing and procurement, conversion, and all logistics management activities. Importantly, it also includes coordination and collaboration with channel partners, which can be suppliers, intermediaries, third-party service providers, and customers. In essence, supply chain management integrates supply and demand management within and across companies. Supply Chain Management is an integrating function with primary responsibility for linking major business functions and business processes within and across companies into a cohesive and high-performing business model. It includes all of the logistics management activities noted above, as well as manufacturing operations, and it drives coordination of processes and activities with and across marketing, sales, product design, and finance and information technology".

From all these perspectives mentioned above and others, I will add the view of $\mathrm{Li}$ (2014) which concludes very simply and specific that:

1) The objective of Supply Chain Management is to be efficient and cost-effective through collaborative efforts across the entire system;

2) The role of Supply Chain Management is to produce products that conform to customer requirements;

3) The scope of Supply Chain Management encompasses the firm 's activities from the strategic level through the tactical and operational levels, since it takes into account the efficient integration of suppliers, manufacturers, wholesalers, logistics providers, retailers, and end users.

Now referring to Logistics, it is mentioned that the concept has existed for centuries. First, the concept was found in military applications. Over time, and because of different changing periods, the appeal to logistics moved into the mainstream business area. We have found numerous definitions for logistics and most of them refer specifically to the physical movement and storage of materials.

According to another author, Martin (2011), Logistics can be defined as the process of strategically managing the procurement, movement and storage of materials, parts and finished inventory (and the related information flows) through the organization and its marketing channels" in a profitably way referring to current and future actions and this through cost-effective fulfilment of orders. From this total systems viewpoint, logistics 
management means concerning on satisfying the needs of customers "through the coordination of the materials and information flows that extend from the marketplace, through the firm and its operations and beyond that to suppliers". In order to achieve this extensive integration of the company, it is clear that is required a quite different orientation that was typically encountered in the conventional companies. Also, in order to achieve this company integration, it is a must the collaborative action of all departments as a synergic process.

Waters (2009) presents Logistics as "the function responsible for the flow of materials from suppliers into an organisation, through operations within the organisation, and then out to customers".

Because Logistics can be explained as the process of observing the circulation of goods in and out the organization, it can be determined the main objective of Logistics, as fulfilling customer satisfaction.

Especially during the 80 's, because of the global competition, companies were forced to provide lower costs, higher quality, more endurable products, and higher product flexibility. In this changing context and because of the changing markets, several programs, techniques and technologies which were directly or indirectly related to Logistics, such as JIT (Just In Time), ECR (Efficient Customer Response), EDI (Electronic Data Interchange), among others, helped for "inventory reductions and better coordination of the material flow along productive chains" (Maia and Cerra, 2009). Understanding the importance and possible benefits of this cooperative relationships with the ones from up and down the flow, suppliers and clients, companies started to think "outside the boundaries". Thus, strategic partnerships started to appear, helping to the building of the Supply Chain Management. This "historical evolution can be considered the first relationship" between Supply Chain Management and Logistics (Maia and Cerra, 2009).

The Council of Supply Chain Management Professionals (CSCMP), also gives information about the relationship between Logistics Management (LM) and Supply Chain Management (SCM). It declares that "Logistics Management is that part of Supply Chain Management that plans, implements, and controls the efficient flow and storage of goods, services and related information between the point of origin and the point of consumption in order to meet customers' requirements" (CSCMP).

Nilsson (2006) thinks that controlling and coordinating logistics activities within and among firms is not easy and the difficulties are expected to increase, because the interdependence among interacting firms is intensifying and is expecting that "systems to exhibit increasingly complex dynamics when changes occur that intensify interactions among elements". Thus, "managing logistics in supply network will create new demands on logistics management" (Nilsson, 2006).

Referring to Logistics Management as a part of Supply Chain Management, it was not always so since Supply Chain Management was introduced into the logistics life cycle only in a late stage, as described and presented above by Globerson and Wolbrum (2014) as the historical development. The origin of logistics thought started around farm-to-market economics, and was first documented around the early 1900s. Globerson and Wolbrum (2014) present in their article the evolution of logistics thought which was divided into the following seven eras: 
- Era 1: Farm to market - this period started around 1900's, and the main focus was only on transportation and distribution.

- Era 2: Military and business - this period started during the Second World War, which pushed the development of functions such as transportation, warehousing, inventory and physical distribution because of the needs that were generated by the war.

- Era 3: Integration of functions - this period started around year 1960, and the main focus of this period was on the total system's performance, rather than on performance of individual functions. Now, logistics started to be taught as an area of interest for the company.

- Era 4: Customer focus - this period started around 1970, when the main focus of the company was customer service and satisfaction.

- Era 5: Logistics strategy - this period started during the 1980`s, when logistics strategy has been considered as a crucial component in the company's strategy. "Emerging concepts are such as Supply Chain Management, environmental logistics, reverse logistics, and a heightened awareness of globalization". In this period, concepts such as information technology and strategy ones have had a major impact.

- Era 6: Integrated Supply Chain Management - this period started during the 1990 's, it was importantly considered to extend logistics processes to the companies involved across the supply chains. "It requires greater involvement with many functional areas within the organizations involved".

- Era 7: International Supply Chain Management - this period started around year 2000 , because of the existence of very effective information technologies, where the chain crosses countries' borders.

Maia and Cerra (2009), reveals that "Logistics is to be a constituting part of Supply Chain Management", which is responsible for the material and information flows between the companies belonging to the same chain. It should not be overlooked that, "Supply Chain Management comprises actions like Sourcing and Procurement, Outsourcing, Partnership relations, Product co-design, etc". However, as it can be seen, there are important conditionings between Logistics and Supply Chain Management and, "in practice, the relationship between both areas is made rather complex given the mutual impacts that decisions made in one area may have on the other".

Another difference between the two concepts is that Logistics Management concentrate more on the micro level of logistics such as "storage and warehouse," whereas Supply Chain Management concentrate more on macro level such as "logistics flow," and "managing the logistics organization." (Globerson and Wolbrum, 2014).

All the activities in a company that are associated with the sourcing, procurement, conversion and logistics management of the raw material that are part of the final product, comes from the supply chain management. Supply Chain Management includes the coordination and collaboration with the ones envolved in the chain like suppliers, intermediaries, distributors and customers in order to bring the right product, in the right time, in the right place, at the right price and this with the help of logistics management. Supply Chain Management connects the first supplier to the last consumer. In other 
words, Logistics Management is a small part of Supply Chain Management that deals with the management of goods in an efficient way.

\section{Conclusions}

So, when we refer to Logistics and Supply Chain Management we can state that these two are no new ideas. Just in the last years business organizations have come to consider the essential impact that logistics management can have in the company for achieving the competitive advantage in the market. Thinking about competition, Michael Porter once said that competition should not be seen as a negative aspect because this can be dangerous to the company and can lead the company to destructive actions. Company should think about competition in a positive way, this means the company must find that way to produce the goods or services in a unique way and to be a company that offers something different from all other products available on the market. The company must focus on how to be a unique company, to produce unique products, to create unique value and have a benefit on the society and this will lead to an advantage over its competitors. And, "a position of enduring superiority over competitors in terms of customer preference may be achieved through better management of logistics and the supply chain" (Martin, 2011).

At the final of the paper, we can say that Supply Chain Management is a bigger concept than Logistics is. Referring to Logistics, this is mainly a planning orientation and framework that seeks to create a single route for the flow of products and information in a business. On this framework Supply Chain Management builds, and seeks to create relationship and coordination between the processes of all companies in involved the chain, such as suppliers and customers, and the company itself. The focus of Supply Chain Management is on building cooperation and gaining trust between entities, and also on the recognition of the synergic effect, that is: "whole can be greater than the sum of its parts". I agree with the definition of Supply Chain Management presented by Martin (2011) which is: "the management of upstream and downstream relationships with suppliers and customers in order to deliver superior customer value at less cost to the supply chain as a whole". In other words, he presents the focus of Supply Chain Management as "the management of relationships in order to achieve a more profitable outcome for all parties in the chain". Not all the time this thing will be easy, because the self-interest of the parties must all the time be subsumed to the benefit of the chain as a whole. "The whole purpose of supply chain management and logistics is to provide customers with the level and quality of service that they require and to do so at less cost to the total supply chain" (Martin, 2011).

It is very important for the company to understand the role that it has in the whole supply chain. By understanding the needs and wishes of the client, as a major decisional factor, the supply chain the company belongs to will develop a complex process of decisions and actions in order to satisfy these needs and finally ensures the competitiveness of the company.

An efficient and effective supply chain, both for the individual members and for the whole, must have as a target the following: a permanent connection to current and future 
needs of the client; a permanent monitoring and minimization of the costs involved in the whole process; a permanent concern for improving the quality of added services.

I will conclude this paper with a quote: Supply chain encompasses the business processes linking the raw material provider to the ultimate customer/consumer. This includes upstream involvement in product development, procurement, operations, logistics, demand/supply planning, and customer service management. (Lamar Johnson, Executive Director, Centre for Customer Insight \& Marketing Solutions and Senior Associate Director, Supply Chain Management Centre of Excellence, The University of Texas at Austin McCombs School of Business)

\section{References}

Bowersox, D.J., Closs, D.J., Cooper, M.B., (2002), Supply chain logistics management, McGrawHill//rwin

Christopher, M., (2016), Logistics \& supply chain management, Pearson Education, New York CSCMP, https://cscmp.org/CSCMP/Academia/SCM_Definitions_and_Glossary_of_Terms/CSCMP/E ducate/SCM_Definitions_and_Glossary_of_Terms.aspx?hkey=60879588-f65f-4ab5-8c4b6878815 ef921

Globerson S., Wolbrum G.,(2014), Logistics management and supply chain management: A critical evaluation, International Journal of Business and Economics Research, 3(2): 82-88

Harrison, A., Hoek, R.V., Skipworth, H., (2014), Logistics Management and Strategy: Competing through the Supply Chain, Pearson Education Limited, Harlow

Larson, P., Halldorsson, A., (2004), Logistics Versus Supply Chain Management: An International Survey, International Journal of Logistics: Research and Applications, Vol. 7, No.1

Li, L. (2014), Managing Supply Chain and Logistics, Competitive Strategy for a Sustainable Future, World Scientific Publishing Company, Singapore

Maia, J.L., Cerra, A.L., (2009), Interrelation between Supply Chain Management and Logistics: a case study in the Brazilian plant of a multinational automotive company, Revista Gestão Industrial, v. 05, n. 01, 59-73

Martin, C., (2011), Logistics and supply chain management : creating value-adding networks, 4 ed., Pearson UK

Nilsson, F. (2006), Logistics management in practice - towards theories of complex logistics. The International Journal of Logistics Management, 17(1), 38-54.

Sweeney, E., Grant, D.B., Mangan, J., (2017), Strategic Adoption Of Logistics And Supply Chain Management, International Journal of Operations \& Production Management, DOI: 10.1108/IJOPM-05-2016-0258

Topps, J., Taylor, G., (2018), Managing the Retail Supply Chain: Merchandising Strategies that Increase Sales and Improve Profitability, Kogan Page Limited, London

Waters, C.D.J., (2009), Supply chain management: An introduction to logistics (Vol. 2). New York: Palgrave Macmillan 